\title{
Prognostic Factors for Post-Recurrence Survival in Stage II and III Colorectal Carcinoma Patients
}

\author{
Neda Nikolic ${ }^{1, *(\mathbb{O})}$, Davorin Radosavljevic ${ }^{1}$, Dusica Gavrilovic ${ }^{1}$, Vladimir Nikolic ${ }^{1}$, Nemanja Stanic ${ }^{1}(\mathbb{D}$, \\ Jelena Spasic $^{1}$, Tamara Cacev ${ }^{2}$, Sergi Castellvi-Bel ${ }^{3}\left(\mathbb{D}\right.$, Milena Cavic ${ }^{1} \mathbb{D}$ and Goran Jankovic ${ }^{4}$ \\ 1 Institute for Oncology and Radiology of Serbia, 11000 Belgrade, Serbia; davorr@ncrc.ac.rs (D.R.); \\ duca@ncrc.ac.rs (D.G.); vladimir.nikolic@ncrc.ac.rs (V.N.); nemanja.s.stanic@gmail.com (N.S.); \\ jelena.spasic@ncrc.ac.rs (J.S.); milena.cavic@ncrc.ac.rs (M.C.) \\ 2 Division of Molecular Medicine, Rudjer Boskovic Institute, 10000 Zagreb, Croatia; tcacev@irb.hr \\ 3 Centro de Investigación Biomédica en Red de Enfermedades Hepáticas y Digestivas (CIBERehd), \\ Gastroenterology Department, Institut d'Investigacions Biomèdiques August Pi i Sunyer (IDIBAPS), \\ Hospital Clínic, University of Barcelona, 08007 Barcelona, Spain; SBEL@clinic.cat \\ 4 Clinic for Gastroenterology and Hepatology, Clinical Centre of Serbia, 11000 Belgrade, Serbia; \\ goran.jankovic@kcs.ac.rs \\ * Correspondence: neda.nikolic@ncrc.ac.rs
}

check for updates

Citation: Nikolic, N.; Radosavljevic, D.; Gavrilovic, D.; Nikolic, V.; Stanic, N.; Spasic, J.; Cacev, T.; Castellvi-Bel, S.; Cavic, M.; Jankovic, G. Prognostic Factors for Post-Recurrence Survival in Stage II and III Colorectal Carcinoma Patients. Medicina 2021, 57, 1108. https://doi.org/10.3390/ medicina57101108

Academic Editor: Gaetano Gallo

Received: 6 September 2021

Accepted: 11 October 2021

Published: 15 October 2021

Publisher's Note: MDPI stays neutral with regard to jurisdictional claims in published maps and institutional affiliations.

Copyright: (C) 2021 by the authors Licensee MDPI, Basel, Switzerland. This article is an open access article distributed under the terms and conditions of the Creative Commons Attribution (CC BY) license (https:/ / creativecommons.org/licenses/by/ $4.0 /)$.

\begin{abstract}
Background and objectives: This study aimed to evaluate prognostic factors for postrecurrence survival in local and locally advanced colorectal cancer patients. Materials and Methods: A total of 273 patients with stage III and high-risk stage II colorectal cancer were prospectively enrolled. All patients underwent operative treatment of the primary tumor and adjuvant fluorouracil-based chemotherapy. Results: Over the three-year period (2008-2010), a cohort of 273 patients with stage III and high-risk stage II colorectal cancer had been screened. During follow up, 105 (38.5\%) patients had disease recurrence. Survival rates 1-, 3- and 5-year after recurrence were 53.9, 18.2 and 6.5\%, respectively, and the median post-recurrence survival time was 13 months. Survival analysis showed that age at diagnosis $(p<0.01)$, gender $(p<0.05)$, elevated postoperative Ca19-9 $(p<0.01)$, tumor histology (adenocarcinoma vs. mucinous vs. signet ring tumors, $p<0.01$ ) and tumor stage (II vs. III, $p<0.05$ ) had a significant influence on post-recurrence survival. Recurrence interval and metastatic site were not related to survival following recurrence. Multivariate analysis showed that older age (HR 2.43), mucinous tumors (HR 1.51) and tumors expressing Ca19-9 at baseline (HR 3.51) were independently associated with survival following recurrence. Conclusions: Baseline patient and tumor characteristics largely predicted patient outcomes after disease recurrence. Recurrence intervals in local and locally advanced colorectal cancer were not found to be prognostic factors for post-recurrence survival. Older age, male gender, stage III and mucinous histology were poor prognostic factors after the disease had recurred. Stage II patients had remarkable post-recurrence survival compared to stage III patients.
\end{abstract}

Keywords: post-recurrence survival; colorectal cancer; prognostic factor

\section{Introduction}

Colorectal cancer (CRC) is the third most commonly diagnosed cancer and one of the leading causes of cancer-related deaths worldwide [1]. In recent years, there has been a steady decline in its overall incidence, due to the implementation of population-based screening programs and rising understanding of the necessity for a healthy lifestyle. Patient survival has also increased due to developments in early diagnosis, personalized therapy and broader knowledge of tumor biology [2]. However, in developing countries, it remains a significant public health burden. In 2018, 4646 new colorectal cancer cases had been diagnosed in Serbia, and 2591 deaths caused by the same cancer had been recorded [3], marking it as the second most common cause of cancer-related morbidity and mortality. 
Approximately $22 \%$ of CRCs are metastatic at initial diagnosis, with a relative 5-year survival rate of $14 \%$, compared to a 71 and $90 \%$ survival rate in those with regional and localized CRC, respectively [2]. A significant number of patients can be cured with surgical resection only [4]. Curative surgery consists of partial colectomy and resection of at least 12 lymph nodes (LNs). Once surgery has been performed, a precise pathohistological report is crucial to stratify the risk of relapse and consequently tailor the individual adjuvant treatment for each patient. The report should consist of bowel wall infiltration (pT-status), number of affected LNs (pN-status), resection margin clearance, differentiation degree, lymphovascular/perineural invasion and microsatellite instability (MSI) status [5,6]. Novel tools for molecular characterization such as next generation sequencing (NGS) and markers such as BRAF (B-Raf proto-oncogene, serine/threonine kinase), RAS (Rat sarcoma virus), CDX2 (Caudal Type Homeobox 2) genes have shown a high prognostic value but have still not been validated for treatment guidance [7-10]. Circulating tumor DNA (ctDNA) is a new rapidly emerging field that may be a good surrogate of minimal residual disease in CRC, which may guide treatment in stage II and III disease in the future [11]. The gene expression-based consensus molecular subtypes (CMS) has been introduced in 2015, as an effort of the international consortium to resolve inconsistencies among the reported gene expression-based CRC classifications. Four robust transcriptome-based subtypes were established: CMS1 (microsatellite instability immune, 14\%); CMS2 (canonical, 37\%); CMS3 (metabolic, 13\%); CMS4 (mesenchymal, 23\%) and samples with mixed features $(13 \%)$ that possibly represent a transition phenotype or intratumoral heterogeneity. Each subtype displays different pathological and genetic signatures. Based on these features, therapeutic stratification for individual patients may be designed, which may ultimately lead to improved therapeutic outcomes [12]. The search for the ideal biomarker for outcome prediction is ongoing and numerous studies so far addressed this issue $[13,14]$.

When diagnosed at a stage when curative resection is possible, the addition of adjuvant chemotherapy provides significant disease-free survival gain that translates into a longterm overall survival benefit [15]. Stage III and high-risk stage II are diagnosed in more than half of patients and curative surgical resection followed by adjuvant chemotherapy is a standard clinical approach. Tumor recurrence is a major obstacle in the cure and long-term survival of patients. Recurrence rates have been reported to be up to $40 \%$ depending on the stage [16]. The probability of recurrence of local and locally advanced CRC is commonly based on predictors present at diagnosis. Prognosis and survival after recurrence of the disease are typically based on tumor and patient characteristics at the time of diagnosis of advanced disease. These include the metastatic site, probability of surgical resection, performance status, and disease burden. Management of advanced CRC is mainly oriented on the recognition of advanced CRC patients as a heterogeneous patient population and, consequently, to a "clinical and molecular" personalized therapy $[17,18]$. Despite aggressive and multimodal treatments, most recurrent patients have a low probability of being cured.

Relatively few studies on prognostic factors for post-recurrence survival (PRS) have been reported. In this study, we aimed to determine whether initial patient characteristics or features of the primary tumor could be relevant factors in predicting future clinical behavior after disease recurrence in patients who had previously undergone complete resection of stage II or III tumors and adjuvant chemotherapy.

\section{Materials and Methods}

\subsection{Patient Characteristics}

Between January 2008 and December 2010, 1187 patients with CRC were treated at the Institute for Oncology and Radiology of Serbia. A total of 273 patients with highrisk stage II and stage III CRC who underwent a complete resection of the primary tumor and were treated with adjuvant chemotherapy had been identified. Among them, $249(91.2 \%)$ patients had colon and $24(8.8 \%)$ proximal rectal cancer. Rectal cancer patients were not subjected to a preoperative treatment due to the localization of the primary tumor. Collected data contain patient characteristics (ECOG PS-Eastern Cooperative Oncology 
group performance status), histopathological reports, recurrence intervals, site of first recurrence, and date of last visit and death. All data were collected from patient medical records or over the telephone, and their association with post-recurrence survival was analyzed. This study was approved by the Institutional Ethics Committee and by the Ethics Committee and Review Board of the University of Belgrade, Serbia (Protocol number 1322/X-40). Signed informed consent was obtained from each patient prior to participation in the study.

Patients were staged according to the 7th TNM (tumor-node-metastasis) staging, proposed by the UICC (Union International for cancer control UICC) [19]. Histologic subtypes of CRC were determined according to World Health Organization classification $[19,20]$. High-risk stage II disease was defined as node-negative disease with high-risk features: T4, lymphovascular invasion, grade 3, intestinal perforation and less than 12 nodes examined in the specimen [20]. For all patients, serum concentrations of CEA (carcinoma embryonic antigen) and Ca19-9 (carbohydrate antigen 19-9) were assessed at baseline (before starting adjuvant chemotherapy).

\subsection{Treatment and Follow-Up}

All patients were treated with adjuvant chemotherapy. The adjuvant chemotherapy consisted of fluorouracil-based chemotherapy, Mayo regimen: 5-fluorouracil $425 \mathrm{mg} / \mathrm{m}^{2}+$ Leucovorin $25 \mathrm{mg} / \mathrm{m}^{2}$, D1-5, Q4W, 6 cycles or Capecitabine, $2500 \mathrm{mg} / \mathrm{m}^{2}$, D1-14, Q3W, 8 cycles, according to the reimbursement list of the Serbian Health Insurance Fund. During the follow-up period, blood examinations (including serum tumor markers CEA, Ca199), chest X-ray or chest/abdomen/pelvis CT scan or abdominal ultrasonography were performed every three months for the first two years after resection and every six months thereafter, according to European Society for Medical Oncology (ESMO) and national guidelines [21]. Patients were followed up until disease recurrence or death from any cause. The criteria for establishing a recurrent disease included radiographic evidence of disease recurrence, clinically palpable mass or histopathology confirmation, if applicable. Recurrences were divided into three groups: local, distant and combined. Local recurrence was defined as recurrence within or contiguous to the previously treated tumor bed and distant recurrence was defined as disease spread outside the primary tumor basin. Recurrence in local lymph nodes was considered as distal spread.

\subsection{Salvage Therapies}

According to the type of salvage treatment after disease recurrence, patients were divided into the following groups: no systemic treatment (patients who were treated with best supportive care (BCS); local radiotherapy (RT) to the bone or brain was allowed), surgery only (patients who were amenable for radical surgery), palliative chemotherapy with and without biologics (patient who were not candidates for curative surgery or radiotherapy) or combination therapy (patients who were treated with combination therapy that included systemic chemotherapy with and without biologics, surgery, and radiotherapy).

\subsection{Statistical Analysis}

Statistical analysis was performed using the program R (version 3.3.2 (31 October 2016)_ “Sincere Pumpkin Patch"; Copyright (C) 2016 The R Foundation for Statistical Computing; Platform: x86_64-w64-mingw32/× 64 (64-bit); downloaded: 21 January 2017) [22]. Curves of probabilities for post-recurrence survival were constructed using the Kaplan-Meier product-limit method; the median of survival analysis with corresponding 95\% CI was used for description and the log-rank test was utilized for testing differences between curves. All reported $p$ values were two-sided, with $p<0.05$ denoting statistical significance. Values over 0.05 were denoted as not statisticaly significant (ns-not significant). Univariate and multivariate Cox proportional hazard regression models were used; the hazard ratio (HR) with the corresponding 95\% CI (confidence interval) were utilized for description; the Wald and Likelihood ratio test was utilized for statistical testing. 


\section{Results}

\subsection{Patient Characteristics}

Out of the 273 patients who underwent curative resection followed by adjuvant chemotherapy for high-risk stage II and III CRC, 105 patients experienced disease recurrence (38.5\%). Median follow-up time was 66 months (range 3-148 months), and the median time to initial recurrence was 17 months. Most patients experienced recurrence in the first year of follow-up (39 patients, $37 \%$ ) and $68.6 \%$ of recurrences were diagnosed in the first 2 years after surgery. Thirteen patients had a recurrence more than four years after the surgery (12.4\%). Post-recurrence survival for the whole group is presented in Figure 1.

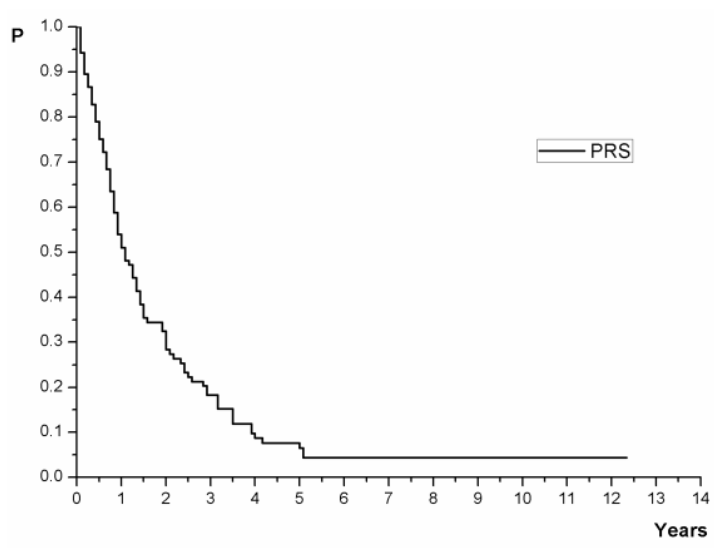

Figure 1. Post-recurrence survival for all patients.

\subsection{Post-Recurrence Survival}

The 1-, 3- and 5-year survival rates of all patients after recurrence were 51.04, 18.24, $6.51 \%$, respectively. The median post-recurrence survival time was 13 months (11-17, $95 \% \mathrm{CI})$. The cumulative percentage of yearly post-recurrence survival during follow-up with $95 \% \mathrm{CI}$ is presented in Table 1.

Table 1. Cumulative percentage of yearly post-recurrence survival.

\begin{tabular}{ccc}
\hline Time & No in Risk & $\begin{array}{c}\text { Cumulative Percentage with } \\
\mathbf{9 5 \%} \text { CI }\end{array}$ \\
\hline 1 year & $56(53.33 \%)$ & $51.04(42.28-61.60)$ \\
2 year & $32(30.48 \%)$ & $28.37(20.85-38.60)$ \\
3 year & $20(19.05 \%)$ & $18.24(12.06-27.60)$ \\
4 year & $9(8.57 \%)$ & $8.69(4.54-16.60)$ \\
5 years & $7(6.67 \%)$ & $6.51(3.04-13.90)$ \\
\hline
\end{tabular}

Differences in post-recurrence survival according to patient characteristics, histopathological findings, pathologic stage, recurrence pattern and time to recurrence is presented in Table 2. 
Table 2. Patient and disease characteristics and influence on post-recurrence survival.

\begin{tabular}{|c|c|c|c|c|c|c|c|}
\hline \multirow[b]{2}{*}{ Characteristic } & \multirow[b]{2}{*}{$N(\%)$} & \multicolumn{2}{|c|}{ Survival (Months) } & \multirow[b]{2}{*}{ Characteristic } & \multirow{2}{*}{$N(\%)$} & \multicolumn{2}{|c|}{ Survival (Months) } \\
\hline & & $\begin{array}{c}\text { Median } \\
(95 \% \text { CI })\end{array}$ & $\begin{array}{c}\text { Log-Rank } \\
\text { Test }\end{array}$ & & & $\begin{array}{c}\text { Median } \\
(95 \% \text { CI) }\end{array}$ & $\underset{\substack{\text { Log-Rank } \\
\text { Test }}}{ }$ \\
\hline Age (years) & & & & Differentiation & & & \\
\hline Mean (SD) & $65.6(10)$ & & & Low grade & $94(89.5 \%)$ & $13(11-17)$ & \\
\hline Median (Range) & $67(20-84)$ & T & T & High grade & $11(10.48 \%)$ & $11(\geq 6)$ & ns \\
\hline Age (categories) & & & & Lymphatic invasion & & & \\
\hline$<70$ yrs & $67(63.8 \%)$ & $18(12-29)$ & & Yes & $73(69.5 \%)$ & $7.5(\geq 5)$ & \\
\hline$\geq 70$ yrs & $38(36.2 \%)$ & $7(5-13)$ & $<0.01$ & No & $14(13.4 \%)$ & $15(11-18)$ & ns \\
\hline Gender & & & & No data & $18(17.1 \%)$ & / & \\
\hline Male & $44(41.9 \%)$ & $9.5(7-16)$ & & Vascular invasion & & & \\
\hline Female & $61(58.1 \%)$ & $17(12-25)$ & $<0.05$ & Yes & $44(41.9 \%)$ & $11(9-30)$ & \\
\hline Localization & & & & No & $35(33.3 \%)$ & $14(9-18)$ & ns \\
\hline Right side & $36(34.3 \%)$ & $10(8-14)$ & & No data & $26(24.8 \%)$ & / & \\
\hline Left side & $69(65.7 \%)$ & $16(12-24)$ & ns & T stage & & & \\
\hline Bowel obstruction & & & & $\mathrm{T} 2$ & $4(3.8 \%)$ & $13(\geq 2)$ & \\
\hline Yes & $33(31.4 \%)$ & 13 (10-29) & & T3 & $84(80 \%)$ & $13(11-18)$ & \\
\hline No & $72(68.6 \%)$ & $13(10-18)$ & ns & $\mathrm{T} 4 \mathrm{a}$ & $3(2.9 \%)$ & $23(\geq 5)$ & ns \\
\hline Bowel perforation & & & & $\mathrm{T} 4 \mathrm{~b}$ & $14(13.3 \%)$ & $9(6-50)$ & \\
\hline Yes & 12 (11.4\%) & $13.5(\geq 10)$ & & N stage & & & \\
\hline No & $93(88.6 \%)$ & $13(10-18)$ & ns & No & $10(9.5 \%)$ & $28.5(\geq 6)$ & \\
\hline ECOG PS † & & & & N1a & $12(11.4 \%)$ & $20.5(\geq 11)$ & \\
\hline PSO & $89(84.8 \%)$ & 12 (10-17) & & N1b & $24(22.9 \%)$ & $16(11-34)$ & \\
\hline PS1 & $16(15.2 \%)$ & $16.5(6-48)$ & ns & $\mathrm{N} 2 \mathrm{a}$ & $24(22.9 \%)$ & $13(10-24)$ & ns \\
\hline CEA & & & & $\mathrm{N} 2 \mathrm{~b}$ & $33(31.4 \%)$ & $9(7-19)$ & \\
\hline$\leq 5 \mathrm{mg} / \mathrm{mL}$ & $86(81.9 \%)$ & $12(10-18)$ & & No data & $2(1.9 \%)$ & / & \\
\hline$>5 \mathrm{ng} / \mathrm{mL}$ & $16(15.2 \%)$ & $14.5(5-42)$ & ns & Stage & & & \\
\hline No data & $3(2.9 \%)$ & / & & II & $9(8.6 \%)$ & $47(\geq 9)$ & \\
\hline Ca19-9 & & & & III & $96(91.4 \%)$ & $13(10-17)$ & $<0.05$ \\
\hline$\leq 37 \mathrm{U} / \mathrm{mL}$ & $91(86.7 \%)$ & 15 (11-18) & & First recurrence & & & \\
\hline$>37 \mathrm{U} / \mathrm{mL}$ & $9(8.6 \%)$ & $8(\geq 4)$ & $<0.01$ & Local & $18(17.1 \%)$ & $20.5(10-42)$ & \\
\hline No data & $5(4.7 \%)$ & $T^{+1}$ & & Systemic disease & $11(10.5 \%)$ & $8(\geq 5)$ & ns \\
\hline Adjuvant CHT & & & & Combined & $76(72.4 \%)$ & $12.5(10-17)$ & \\
\hline 5FU-LV & $37(35.2 \%)$ & $23(11-34)$ & $\mathrm{ns}$ & Early recurrence & & & \\
\hline Capecitabine & $68(64.8 \%)$ & $11(9-16)$ & ns & $<1$ year & $39(37.1 \%)$ & $11(10-19)$ & \\
\hline Histology & & & & $\geq 1$ year & $66(62.9 \%)$ & $13(10-23)$ & ns \\
\hline Adenocarcinoma & $93(88.6 \%)$ & 15 (11-19) & & Late recurrence & & & \\
\hline Mucinous & $10(9.5 \%)$ & $8.5(\geq 6)$ & $<0.01$ & $\geq 4$ years & $13(12.4 \%)$ & $10(\geq 6)$ & \\
\hline Signet ring & $2(1.9 \%)$ & $4(\geq 1)$ & & $<4$ years & $92(87.6 \%)$ & $13.5(12-18)$ & ns \\
\hline
\end{tabular}

Survival analysis showed that age at diagnosis, gender, elevated postoperative Ca19-9, tumor histology and tumor stage had a statistically significant influence on post-recurrence survival. Survival following recurrence was strongly affected by age at diagnosis, showing worse outcomes in patients of 70 years or older, who had only 7 months of post-recurrence survival compared with 18 months in patients under $70(p<0.01$; Table 2). An influence of gender was detected, with a worse outcome for male patients (median 17 vs. 9.5 months, respectively, $p<0.05$, Table 2). Histopathology was strongly related to survival following recurrence, indicating worse outcomes for mucinous and signet ring tumors. Median post-recurrence survival was 15 vs. 8.5 vs. 4 months for adenocarcinoma, mucinous and signet ring tumors, respectively ( $p<0.01$, Table 2$)$. Patients who initially had a high level of postoperative Ca19-9 ( $\geq 37$ ) had worse survival following recurrence than patients with normal Ca19-9 levels at baseline ( $p<0.01$, Table 2).

In patients with stage II disease, the 5-year post-recurrence survival rate reached $27.8 \%$ and median survival was 47 months, whilst for stage III tumors the 5-year post-recurrence survival rate was $4.7 \%$ and median survival was 13 months $(p<0.05)$. Time from diagnosis to recurrence and site of metastasis were not related to survival following recurrence. Kaplan-Meier plots for post-recurrence survival according to investigated variables are shown in Figure 2. 

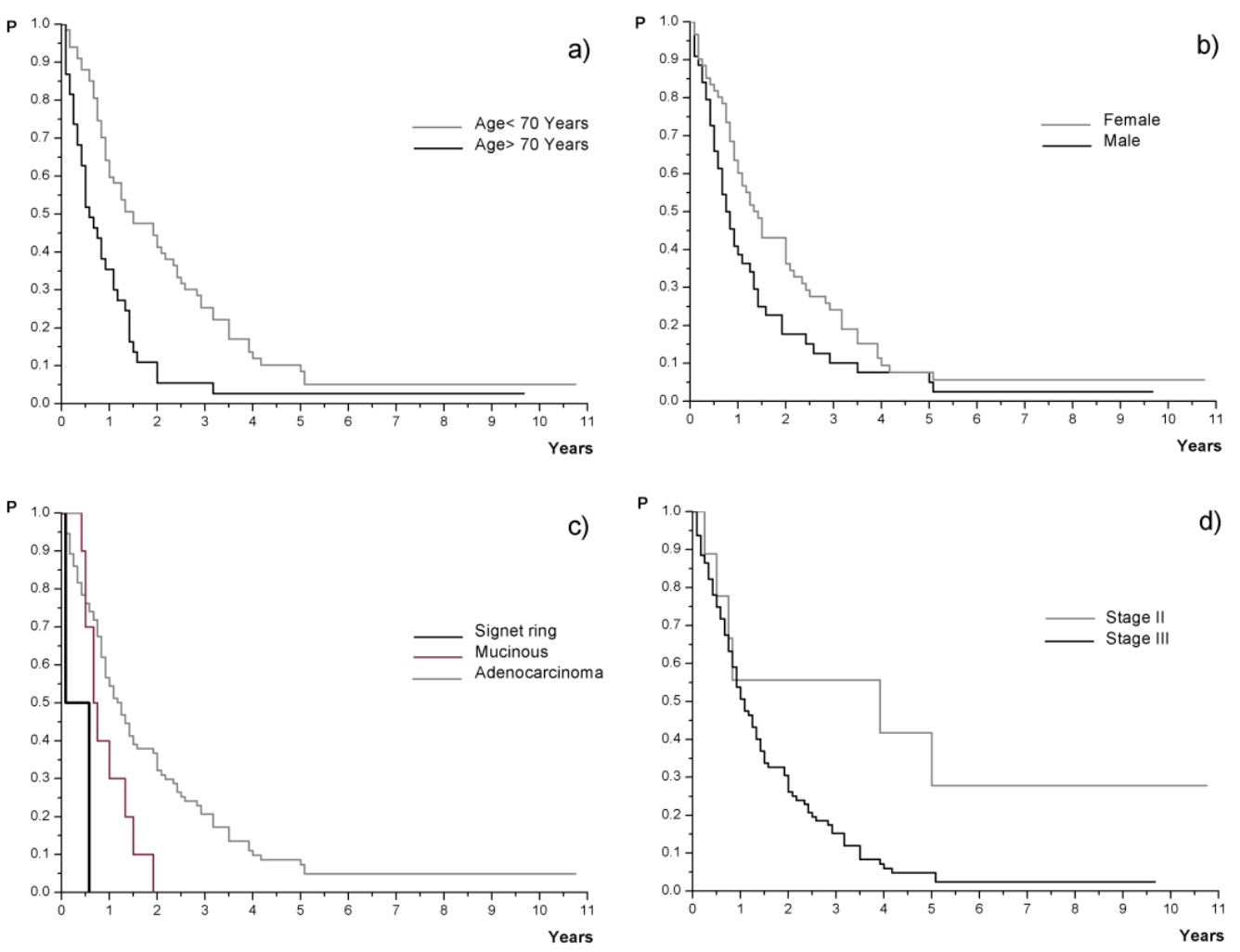

Figure 2. Kaplan-Meier curves for post-recurrence survival according to (a) age at diagnosis, $p<0.01$; (b) gender, $p<0.05$; (c) histology, $p<0.01$; (d) clinical stage at diagnosis, $p<0.05$.

Parameters that were statistically significant in the log-rank test were further assessed using the univariate and multivariate Cox regression analysis. Multivariate analysis showed that (95\% CI): older age (HR 2.43, range: 1.55-3.81), signet ring carcinoma (HR 9.69, range: 2.23-41.9), mucinous tumors (HR 1.51, range 0.73-3.10) and tumors expressing Ca19-9 at baseline (HR 3.51, range 1.68-7.37) were independently associated with survival following recurrence (Table 3).

Table 3. Univariate and multivariate analyses of prognostic factors for post-recurrence survival.

\begin{tabular}{|c|c|c|c|c|}
\hline \multirow{2}{*}{ Parameters } & \multicolumn{2}{|c|}{ Univariate Cox Regression } & \multicolumn{2}{|c|}{ Multivariate Cox Regression } \\
\hline & $\operatorname{HR}(95 \% \mathrm{CI})$ & Wald Test & HR (95\% CI) & $\begin{array}{c}\text { Likelihood } \\
\text { Ratio Test }\end{array}$ \\
\hline Age & & & & \\
\hline$\geq 70$ yrs vs. $<70$ yrs & $2.19(1.42-3.38)$ & $p<0.01$ & $2.43(1.55-3.81)$ & \\
\hline Gender & & & - & \\
\hline $\begin{array}{c}\text { Male vs. Female } \\
\text { Histology }\end{array}$ & $1.45(0.96-2.19)$ & ns & - & \\
\hline Mucinous vs. & & & & \\
\hline Adenocarcinoma & $2.07(1.02-4.20)$ & $p<0.05$ & $1.51(0.73-3.10)$ & $p<0.01$ \\
\hline Signet ring vs. & $6.73(1.58-28.58)$ & $p<0.05$ & $9.69(2.23-42.0)$ & \\
\hline Adenocarcinoma & & & & \\
\hline Clinical stage & & & & \\
\hline $\begin{array}{c}\text { Stage III vs. Stage II } \\
\text { Ca19-9 }\end{array}$ & $2.64(1.13-6.17)$ & $p<0.05$ & - & \\
\hline $\begin{array}{c}>37 \mathrm{U} / \mathrm{ml} \text { vs. } \leq 37 \\
\mathrm{U} / \mathrm{mL}\end{array}$ & $2.71(1.33-5.52)$ & $p<0.05$ & $3.51(1.68-7.37)$ & \\
\hline
\end{tabular}

\subsection{Salvage Therapies}

Out of 105 patients with recurrent disease, 22.8\% (24) were not amenable to systemic treatment at diagnosis of metastatic disease. All of them were treated with best supportive 
care; in four patients, radiotherapy to the bone was the only treatment, and one patient had radiotherapy to the brain. The type of salvage treatment and their influence on survival are presented in Table 4 and Figure 3. The longest survival was observed in the group who were treated with upfront resection, as the only treatment modality (38.5 months). Patients who were treated with combined treatment and chemotherapy only had a post-recurrence survival of 24 and 13 months, respectively. Patients who were not amenable to systemic treatment had the worst median post-recurrence survival of only 3 months.

Table 4. Salvage treatments and their influence on survival.

\begin{tabular}{cccc}
\hline Salvage Treatment & $\boldsymbol{N}(\%)$ & $\begin{array}{c}\text { Median Survival (Months) } \\
\mathbf{9 5 \%} \text { CI }\end{array}$ & $\begin{array}{c}\text { Log-Rank } \\
\text { Test }\end{array}$ \\
\hline BSC +/- local RT & $24(22.8 \%)$ & $3(2-5)$ & \\
Surgery only & $8(7.6 \%)$ & $38.5(23-\mathrm{NR})$ & $<0.01$ \\
Chemotherapy only & $41(39 \%)$ & $13(10-19)$ & \\
Combined treatment & $24(22.9 \%)$ & $24(17-42)$ & \\
\hline
\end{tabular}

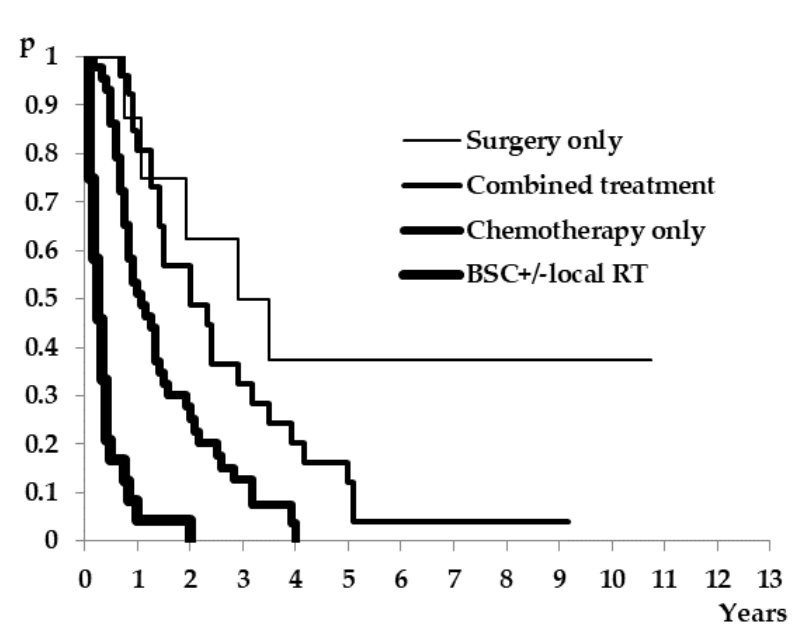

Figure 3. Kaplan-Meier curves for post-recurrence survival according to salvage treatments.

\section{Discussion}

In this study, the risk factors affecting post-recurrence survival of patients with local and locally advanced CRC who underwent surgical resection followed by adjuvant chemotherapy were analyzed. CRC is a growing public health problem in Serbia and worldwide, yet there is scarce available data on prognostic factors and patient outcomes. The obtained data indicated that patients' age ( $>70$ years) as well as mucinous histology were independent predictors of post-recurrence survival. The influence of the time to recurrence on post-recurrence survival was not confirmed. Stage at diagnosis was a prognostic factor for post-recurrence survival, but not an independent one.

Older patients comprise a majority of diagnosed CRC, as $60 \%$ of them are older than 70 years at the time of diagnosis. Patients older than 75 years also account for half of CRC deaths [2]. In general, survival of cancer patients usually decreases with age [23,24]. Survival of older patients is not only limited by their primary disease itself, but rather by their comorbidities, frailty, and psychological and social care issues. In their study, Doat et al. concluded that with increasing age, overall survival, and thus follow-up, decreases-as does the intensity of cancer treatment [25]. Our group comprised of $63.8 \%$ patients older than 70 years at the time of diagnosis of primary CRC. All of them were treated with adjuvant chemotherapy. When disease recurred, older age was found to be an independent poor prognostic factor for survival following recurrence in the multivariate analysis. Previously published large cohort studies had found an inverse relationship between age and survival $[26,27]$. This fact does not come as a surprise; younger patients are expected to 
have longer survival times, as they have fewer comorbidities, lower probabilities of dying from other causes and are likely to receive more aggressive treatments [28].

Differences in CRC survival relating to patients' gender have been observed in previously published studies. A consistent higher rate of survival in female patients has been reported [29-32]. The difference is most prominent in young and middle-aged patients [29]. The observed trend might be attributed to sex hormones, higher levels of health awareness and potential differences in risk behaviors (smoking, physical inactivity, etc.) [32]. Our data confirmed gender-dependent differences in post-recurrence survival. It was not confirmed as an independent predictor in the multivariate model - the rationale for which might be the lack of age-stratification. Further research on these aspects should be pursued.

Different origins of the right and left side of the colon lead to differences in clinical behavior, and chemo and biological therapy response according to the side of the primary tumor [33]. The influence of the sidedness of the primary tumor in prognosis is still debatable and is largely impacted by the stage of the disease [34]. Our data showed a trend of longer post-recurrence survival in patients with left-sided tumors, who had a survival time 6 months longer compared to patients with right-sided tumors. The observed result failed to reach statistical significance, probably due to the small sample size. In stage IV $\mathrm{CRC}$, the side of the primary tumor is an important determinant and should be taken into account when analyzing the prognosis of individual patients.

Previous studies identified Ca19-9 as a prognostic factor in CRC [35,36]. Elevated baseline Ca19-9 was attributed to a high risk of postoperative metastasis, which contributes to a worse survival rate. This study confirmed the prognostic significance of Ca19-9, even for post-recurrence survival. Although evaluation of postoperative Ca19-9 levels is not recommended by the prominent guidelines, the clinical value of Ca19-9 measurement is undoubted. It showed a strong prognostic influence in our study and might be proposed as a minimally-invasive, low-cost prognostic marker in this setting.

Mucinous adenocarcinomas are a rare and distinct entity of CRC. Conflicting data on prognosis and survival of signet ring cell and mucinous adenocarcinomas exists, since most of the data comes from retrospective series [37]. In this study group, the frequencies of mucinous and signet ring histology tumors were as expected, at $9.5 \%$ and less than $2 \%$, respectively. Non-adenocarcinoma histology was confirmed as an independent factor for post-recurrence prognosis (HR for mucinous 1.506; HR for signet ring 9.687). This observation can be attributed to clinical and genetic characteristics of mucinous cancers and poor responses to palliative systemic therapy compared to standard adenocarcinoma [38].

Stage remains one of the most important prognostic factors for survival of CRC patients. Regarding the influence of stage at diagnosis, patients with stage II had an outstanding survival following recurrence that reached 47 months. In stage III, median post-recurrence survival was only 13 months $(p<0.05)$. Although this difference was clinically and statistically significant, it did not prove to be an independent factor for post-recurrence survival in the multivariate analysis. The reason might lie in the small sample size of stage II patients, as less than $10 \%$ of analyzed patients had stage II and tumor recurrence.

$\mathrm{O}^{\prime}$ Connell et al. explored survival following recurrences in patients from ACCENT database in 2008 [39]. They concluded that stage of the disease and recurrence interval were independent predictors for post-recurrence survival. Particularly, in patients with initial stage III disease, time from randomization was significantly associated with survival following recurrence, but not in patients with initial stage II disease. Other retrospective observational studies have confirmed that patients who had shorter DFS ( $<12$ months) have poorer outcomes [40,41]. Recurrence in the first two years of follow up is a poor prognostic factor as well [42]. These data are in accordance with the concept that the biology of fast recurring cancers contributes to their aggressiveness and renders them less likely to be impacted by adjuvant chemotherapy. However, this was not reflected in the results of this study. Almost $40 \%$ of recurrences were diagnosed in the first year of follow up, but data do not support the poor outcome of this group. Early recurrence had no 
impact on post-recurrence survival. This result could only be explained with regard to missing stage stratification. Stage II tumors tend to have longer post-recurrence survival in general. Stratification based on stages at diagnosis could provide better insight into this matter. Broadbridge et al. in 2013 have explored the prognosis of late recurring cancers (more than 5 years from diagnosis) and found no survival differences between early and late recurrences of colon cancer [43]. Expected 'indolent' biology, and thus better survival in late recurring cancers, could not be confirmed. Late recurrences were more common in older patients, left-sided colon cancer and stage II. We reached similar results in our research. Late recurrence did not lead to prolonged post-recurrence survival. These results clearly point out that the recurrence interval could not be used as a single independent prognostic determinant of individual patients.

When a diagnosis of metastatic disease is reached, further treatment options are explored depending on patient- and disease-related relevant factors. Patient-related factors taken into consideration are performance status, symptom burden, comorbidities, patient expectation and motivation. Disease-related factors combine patterns of tumor biology and clinical presentation of the disease. The treatment strategy is established by defining a treatment aim and the possibility of a multimodal approach. In our group, $22.8 \%$ of patients didn't receive any systemic treatment and this group had the worst survival, as expected. The best post-recurrence survival was shown for patients who were treated with upfront resection where that was the only treatment modality throughout the course of their metastatic disease. This clinical setting was possible due to 'good' tumor biology and metastases that were limited in number and size. Good long-term survival was also achieved in the group of patients who were treated with combined therapies-surgery, chemotherapy (with or without biologics) and radiotherapy. In the group of patients who received systemic treatment, the shortest survival was seen in patients with non-resectable metastatic disease and with palliative treatment intentions.

To the best of our knowledge, this is the first study of this type performed on the Slavic population in the Western Balkan area which is combined with results on the genetic background of patients [44-46] might be useful for future meta-analyses, as various population-based factors might also be significant.

\section{Conclusions}

Baseline patient and tumor characteristics largely predict a patient's outcome after disease recurrence. Older age, male gender and mucinous histology were confirmed as poor prognostic factors for recurrent disease. Stage II patients had remarkable postrecurrence survival compared to stage III patients. The recurrence interval was not found to be a prognostic factor for post-recurrence survival of colorectal cancer patients. Short $(<1$ year) or long ( $>4$ years) intervals between resection and recurrence of the primary tumor were not associated with a poorer prognosis. In a country with limited resources, baseline tumor and patient characteristics provide clinically significant factors in defining individual prognosis of patients with recurrent CRC.

Author Contributions: Conceptualization: N.N., D.R., G.J.; Methodology: N.N., D.R.; Validation: J.S., M.C., V.N., T.C., S.C.-B.; Formal Analysis: D.G., N.S.; Investigation: N.N.; Resources: N.N., M.C.; Data Curation: N.N.; Writing-Original D.R. aft Preparation: N.N.; Writing-Review and Editing: N.N., J.S., V.N., T.C., S.C.-B.; Visualization: N.N.; Supervision: D.R., G.J.; Project Administration: V.N., N.S.; Funding Acquisition: M.C. All authors have read and agreed to the published version of the manuscript.

Funding: This study is supported by the Ministry of Education and Science of the Re-public of Serbia (Agreement No. 451-03-9/2021-14/200043). This article is based upon work from COST Action CA17118, supported by COST (European Cooperation in Science and Technology); www.cost.eu (accessed on 12 October 2021). 
Institutional Review Board Statement: The study was conducted according to the guidelines of the Declaration of Helsinki, and approved by the Ethics Committee and Review Board of the University of Belgrade, Serbia (Protocol number 1322/X-40, date: 1 October 2020).

Informed Consent Statement: Signed informed consent was obtained from all subjects involved in the study.

Data Availability Statement: Data available on request due to privacy restrictions.

Acknowledgments: JS and MC are supported by the Science Fund of the Republic of Serbia (PROMIS TRACEPIGEN project No. 6060876).

Conflicts of Interest: The authors declare no conflict of interest.

\section{References}

1. Sung, H.; Ferlay, J.; Siegel, R.L.; Laversanne, M.; Soerjomataram, I.; Jemal, A.; Bray, F. Global Cancer Statistics 2020: GLOBOCAN Estimates of Incidence and Mortality Worldwide for 36 Cancers in 185 Countries. CA Cancer J. Clin. 2021, 71, 209-249. [CrossRef]

2. Howlader, N.; Noone, A.M.; Krapcho, M.; Miller, D.; Brest, A.; Yu, M. SEER Cancer Statistics Review, 1975-2016; National Cancer Institute: Bethesda, MD, USA, 2020.

3. Batut, M.J. (Ed.) Maligni tumori u Republici Srbiji; Institut za javno zdravlje Srbije: Beograd, Serbia, 2018; ISBN 978-86-7358-111-8. (In Serbian)

4. Siegel, R.L.; Miller, K.D.; Fedewa, S.A.; Ahnen, D.J.; Meester, R.G.S.; Barzi, A.; Jemal, A. Colorectal cancer statistics, 2017. CA Cancer J. Clin. 2017, 67, 177-193. [CrossRef]

5. Compton, C.C.; Fielding, L.P.; Burgart, L.J.; Conley, B.; Cooper, H.S.; Hamilton, S.R.; Hammond, M.E.H.; Henson, D.E.; Hutter, R.V.P.; Nagle, R.B.; et al. Prognostic Factors in Colorectal Cancer. Arch. Pathol. Lab. Med. 2000, 124, 979-994. [CrossRef] [PubMed]

6. Washington, M.K.; Berlin, J.; Branton, P.; Burgart, L.J.; Carter, D.K.; Fitzgibbons, P.L.; Halling, K.; Frankel, W.; Jessup, J.; Kakar, S.; et al. Protocol for the Examination of Specimens From Patients With Primary Carcinoma of the Colon and Rectum. Arch. Pathol. Lab. Med. 2009, 133, 1539-1551. [CrossRef] [PubMed]

7. Gunderson, L.L.; Jessup, J.M.; Sargent, D.J.; Greene, F.L.; Stewart, A.K. Revised TN Categorization for Colon Cancer Based on National Survival Outcomes Data. J. Clin. Oncol. 2010, 28, 264-271. [CrossRef] [PubMed]

8. Tarazona, N.; Gimeno-Valiente, F.; Gambardella, V.; Zuniga, S.; Rentero-Garrido, P.; Huerta, M.; Roselló, S.; Martinez-Ciarpaglini, C.; Carbonell-Asins, J.; Carrasco, F.; et al. Targeted next-generation sequencing of circulating-tumor DNA for tracking minimal residual disease in localized colon cancer. Ann. Oncol. 2019, 30, 1804-1812. [CrossRef]

9. Schmoll, H.J.; Van Cutsem, E.; Stein, A.; Valentini, V.; Glimelius, B.; Haustermans, K.; Nordlinger, B.; van de Velde, C.J.; Balmaña, J.; Regula, J.; et al. ESMO Consensus Guidelines for management of patients with colon and rectal cancer. A personalized approach to clinical decision making. Ann. Oncol. 2012, 23, 2479-2516. [CrossRef] [PubMed]

10. Dienstmann, R.; Mason, M.J.; Sinicrope, F.A.; Phipps, A.I.; Tejpar, S.; Nesbakken, A.; Danielsen, S.A.; Sveen, A.; Buchanan, D.D.; Clendenning, M.; et al. Prediction of overall survival in stage II and III colon cancer beyond TNM system: A retrospective, pooled biomarker study. Ann. Oncol. 2017, 28, 1023-1031. [CrossRef]

11. Reinert, T.; Schøler, L.V.; Thomsen, R.; Tobiasen, H.; Vang, S.; Nordentoft, I.; Lamy, P.; Kannerup, A.-S.; Mortensen, F.V.; Stribolt, K.; et al. Analysis of circulating tumour DNA to monitor disease burden following colorectal cancer surgery. Gut 2015, 65, 625-634. [CrossRef]

12. Guinney, J.; Dienstmann, R.; Wang, X.; de Reyniès, A.; Schlicker, A.; Soneson, C.; Marisa, L.; Roepman, P.; Nyamundanda, G.; Angelino, P.; et al. The consensus molecular subtypes of colorectal cancer. Nat. Med. 2015, 21, 1350-1356. [CrossRef]

13. Dienstmann, R.; Villacampa, G.; Sveen, A.; Mason, M.J.; Niedzwiecki, D.; Nesbakken, A.; Moreno, V.; Warren, R.S.; Lothe, R.A.; Guinney, J. Relative contribution of clinicopathological variables, genomic markers, transcriptomic subtyping and microenvironment features for outcome prediction in stage II/III colorectal cancer. Ann. Oncol. 2019, 30, 1622-1629. [CrossRef]

14. Sammarco, G.; Gallo, G.; Vescio, G.; Picciariello, A.; De Paola, G.; Trompetto, M.; Currò, G.; Ammendola, M. Mast Cells, microRNAs and Others: The Role of Translational Research on Colorectal Cancer in the Forthcoming Era of Precision Medicine. J. Clin. Med. 2020, 9, 2852. [CrossRef]

15. Sargent, D.; Sobrero, A.; Grothey, A.; O'Connell, M.J.; Buyse, M.; André, T.; Zheng, Y.; Green, E.; Labianca, R.; O'Callaghan, C.; et al. Evidence for Cure by Adjuvant Therapy in Colon Cancer: Observations Based on Individual Patient Data From 20,898 Patients on 18 Randomized Trials. J. Clin. Oncol. 2009, 27, 872-877. [CrossRef]

16. Jeffery, M.; Hickey, B.; Hider, P.N.; See, A.M. Follow-up strategies for patients treated for non-metastatic colorectal cancer. Cochrane Database Syst. Rev. 2016, 11, CD002200. [CrossRef]

17. Molinari, C.; Marisi, G.; Passardi, A.; Matteucci, L.; De Maio, G.; Ulivi, P. Heterogeneity in Colorectal Cancer: A Challenge for Personalized Medicine? Int. J. Mol. Sci. 2018, 19, 3733. [CrossRef]

18. Goey, K.K.; Sørbye, H.; Glimelius, B.; Adams, R.A.; André, T.; Arnold, D.; Berlin, J.D.; Bodoky, G.; de Gramont, A.; Díaz-Rubio, E.; et al. Consensus statement on essential patient characteristics in systemic treatment trials for metastatic colorectal cancer: Supported by the ARCAD Group. Eur. J. Cancer 2018, 100, 35-45. [CrossRef] [PubMed] 
19. Sobin, L.H.; Gospodarowicz, M.K.; Wittekind, C. TNM Classification of Malignant Tumors, 7th ed.; Wiley-Blackwell: Oxford, UK, 2009.

20. Bosman, F.T.; Carneiro, F.; Hruban, R.H.; Theise, N.D. Carcinoma of the colon and rectum. In WHO Classification of Tumours of the Digestive System, 4th ed.; IARC Press: Lyon, France, 2010; pp. 134-144.

21. Labianca, R.; Nordlinger, B.; Beretta, G.D.; Mosconi, S.; Mandalà, M.; Cervantes, A.; Arnold, D. Early colon cancer: ESMO Clinical Practice Guidelines for diagnosis, treatment and follow-up. Ann. Oncol. 2013, 24, vi64-vi72. [CrossRef] [PubMed]

22. The R Foundation for Statistical Computing; Platform: x86_64-w64-mingw32/x64 (64-bit); "Sincere Pumpkin Patch"; Copyright (C). 2016. Available online: https:/ / www.r-project.org/ (accessed on 21 January 2017).

23. Joachim, C.; Macni, J.; Drame, M.; Pomier, A.; Escarmant, P.; Veronique-Baudin, J.; Vinh-Hung, V. Overall survival of colorectal cancer by stage at diagnosis. Medicine 2019, 98, e16941. [CrossRef] [PubMed]

24. Lieu, C.H.; Renfro, L.A.; De Gramont, A.; Meyers, J.P.; Maughan, T.S.; Seymour, M.T.; Saltz, L.; Goldberg, R.M.; Sargent, D.J.; Eckhardt, S.G.; et al. Association of Age With Survival in Patients With Metastatic Colorectal Cancer: Analysis From the ARCAD Clinical Trials Program. J. Clin. Oncol. 2014, 32, 2975-2982. [CrossRef]

25. Doat, S.; Thiébaut, A.; Samson, S.; Ricordeau, P.; Guillemot, D.; Mitry, E. Elderly patients with colorectal cancer: Treatment modalities and survival in France. National data from the ThInDiT cohort study. Eur. J. Cancer 2014, 50, 1276-1283. [CrossRef] [PubMed]

26. Shack, L.; Shah, A.; Lambert, P.; Rachet, B. Cure by age and stage at diagnosis for colorectal cancer patients in North West England, 1997-2004: A population-based study. Cancer Epidemiol. 2012, 36, 548-553. [CrossRef] [PubMed]

27. Steele, S.R.; Park, G.E.; Johnson, E.K.; Martin, M.J.; Stojadinovic, A.; Maykel, J.A.; Causey, M.W. The Impact of Age on Colorectal Cancer Incidence, Treatment, and Outcomes in an Equal-Access Health Care System. Dis. Colon Rectum 2014, 57, 303-310. [CrossRef]

28. Berian, J.R.; Benson, A.B.; Nelson, H.; Iii, A.B.B. Young Age and Aggressive Treatment in Colon Cancer. JAMA 2015, 314, 613-614. [CrossRef]

29. Global Burden of Disease Cancer Collaboration; Fitzmaurice, C.; Abate, D.; Abbasi, N.; Abbastabar, H.; Abd-Allah, F.; AbdelRahman, O.; Abdelalim, A.; Abdoli, A.; Abdollahpour, I.; et al. Global, Regional, and National Cancer Incidence, Mortality, Years of Life Lost, Years Lived With Disability, and Disability-Adjusted Life-Years for 29 Cancer Groups, 1990 to 2017: A System-atic Analysis for the Global Burden of Disease Study. JAMA Oncol. 2019, 5, 1749-1768. [CrossRef]

30. Majek, O.; Gondos, A.; Jansen, L.; Emrich, K.; Holleczek, B.; Katalinic, A.; Nennecke, A.; Eberle, A.; Brenner, H.; The GEKID Cancer Survival Working Group. Sex Differences in Colorectal Cancer Survival: Population-Based Analysis of 164,996 Colorectal Cancer Patients in Germany. PLoS ONE 2013, 8, e68077. [CrossRef]

31. Yang, Y.; Wang, G.; He, J.; Ren, S.; Wu, F.; Zhang, J.; Wang, F. Gender differences in colorectal cancer survival: A meta-analysis. Int. J. Cancer 2017, 141, 1942-1949. [CrossRef]

32. Samawi, H.H.; Yin, Y.; Speers, C.H.; Cheung, W.Y. Sex Disparities in Outcomes of Early Stage Colorectal Cancer: A PopulationBased Study. Clin. Colorectal Cancer 2018, 17, e711-e717. [CrossRef]

33. Li, Y.; Feng, Y.; Dai, W.; Li, Q.; Cai, S.; Peng, J. Prognostic Effect of Tumor Sidedness in Colorectal Cancer: A SEER-Based Analysis. Clin. Colorectal Cancer 2019, 18, e104-e116. [CrossRef] [PubMed]

34. Cascinu, S.; Poli, D.; Zaniboni, A.; Lonardi, S.; Labianca, R.; Sobrero, A.; Rosati, G.; Di Bartolomeo, M.; Scartozzi, M.; Zagonel, V.; et al. The prognostic impact of primary tumour location in patients with stage II and stage III colon cancer receiving adjuvant therapy. A GISCAD analysis from three large randomised trials. Eur. J. Cancer 2019, 111, 1-7. [CrossRef]

35. Zhou, W.; Yang, F.; Peng, J.; Wang, F.; Lin, Y.; Jiang, W.; Yang, X.; Li, L.; Lu, Z.; Wan, D.; et al. High pretreatment serum CA19-9 level predicts a poor prognosis for patients with stage III colon cancer after curative resection and adjuvant chemotherapy. $J$. Cancer 2019, 10, 3810-3818. [CrossRef] [PubMed]

36. Sato, H.; Kotake, K.; Sugihara, K.; Takahashi, H.; Maeda, K.; Uyama, I. Clinicopathological Factors Associated with Recurrence and Prognosis after R0 Resection for Stage IV Colorectal Cancer with Peritoneal Metastasis. Dig. Surg. 2016, 33, 382-391. [CrossRef]

37. Kang, H.; O'Connell, J.B.; Maggard, M.A.; Sack, J.; Ko, C.Y. A 10-Year Outcomes Evaluation of Mucinous and Signet-Ring Cell Carcinoma of the Colon and Rectum. Dis. Colon Rectum 2005, 48, 1161-1168. [CrossRef] [PubMed]

38. Khan, M.; Loree, J.; Advani, S.M.; Ning, J.; Li, W.; Pereira, A.A.; Lam, M.; Raghav, K.; Morris, V.K.; Broaddus, R.; et al. Prognostic Implications of Mucinous Differentiation in Metastatic Colorectal Carcinoma Can Be Explained by Distinct Molecular and Clinicopathologic Characteristics. Clin. Colorectal Cancer 2018, 17, e699-e709. [CrossRef]

39. O'Connell, M.J.; Campbell, M.E.; Goldberg, R.M.; Grothey, A.; Seitz, J.-F.; Benedetti, J.K.; André, T.; Haller, D.G.; Sargent, D. Survival Following Recurrence in Stage II and III Colon Cancer: Findings From the ACCENT Data Set. J. Clin. Oncol. 2008, 26, 2336-2341. [CrossRef] [PubMed]

40. Lin, B.-R.; Chang, T.-C.; Lee, Y.-C.; Lee, P.-H.; Chang, K.-J.; Liang, J.-T. Pulmonary Resection for Colorectal Cancer Metastases: Duration Between Cancer Onset and Lung Metastasis as an Important Prognostic Factor. Ann. Surg. Oncol. 2009, 16, 1026-1032. [CrossRef]

41. Gonzalez, M.; Robert, J.H.; Halkic, N.; Mentha, G.; Roth, A.; Perneger, T.; Ris, H.B.; Gervaz, P. Survival after Lung Metastasectomy in Colorectal Cancer Patients with Previously Resected Liver Metastases. World J. Surg. 2011, 36, 386-391. [CrossRef] [PubMed] 
42. Ryuk, J.P.; Choi, G.-S.; Park, J.S.; Kim, H.J.; Park, S.Y.; Yoon, G.S.; Jun, S.H.; Kwon, Y.C. Predictive factors and the prognosis of recurrence of colorectal cancer within 2 years after curative resection. Ann. Surg. Treat. Res. 2014, 86, 143-151. [CrossRef]

43. Broadbridge, V.T.; Karapetis, C.; Beeke, C.; Woodman, R.; Padbury, R.; Maddern, G.; Kim, S.W.; Roder, D.; Hakendorf, P.; Price, T.J. Do metastatic colorectal cancer patients who present with late relapse after curative surgery have a better survival? Br. J. Cancer 2013, 109, 1338-1343. [CrossRef]

44. Brotto, K.; Malisic, E.; Cavic, M.; Krivokuca, A.; Jankovic, R. The Usability of Allele-Specific PCR and Reverse-Hybridization Assays for KRAS Genotyping in Serbian Colorectal Cancer Patients. Dig. Dis. Sci. 2012, 58, 998-1003. [CrossRef]

45. Jakovljevic, K.; Malisic, E.; Cavic, M.; Krivokuca, A.; Dobricic, J.; Jankovic, R. KRAS and BRAF mutations in Serbian patients with colorectal cancer. J. BUON 2012, 17, 575-580.

46. Cavic, M.; Krivokuca, A.; Boljevic, I.; Brotto, K.; Jovanovic, K.; Tanic, M.; Filipovic, L.; Zec, M.; Malisic, E.; Jankovic, R.; et al. Pharmacogenetics in cancer therapy -8 years of experience at the Institute for Oncology and Radiology of Serbia. J. BUON 2016, 21, 1287-1295. [PubMed] 